\title{
Increasing the Brand Awareness of Sans Power's Consumers in its Marketing Booklet
}

\author{
Claudia Marselina \\ English Department, Faculty of Languages and Literature, Petra Christian University, Siwalankerto 121-131, \\ Surabaya 60236, INDONESIA \\ e-mail: claudiamarselina@gmail.com
}

\begin{abstract}
This paper aims at overcoming the problem faced by Sans Power by creating a marketing booklet as the solution. Sans Power is a trading company selling solar-energy products, like solar water pumps and solar panels. It offers a variety of solar water pumps based on the function, which are Submersible Solar Pump, Surface Solar Pump, and Solar Pool Pump. The main problem Sans Power is currently facing is the salespeople find it hard to explain to its customers and prospects about the uniqueness of buying Sans Power's products. Therefore, a marketing booklet emphasizing the uniqueness of the products would be a solution. The marketing booklet will become the tool for the sales and marketing team to offer the unique benefits the customers can get. It will also make customers know more about Sans Power's products and services, which can attract them increasing the sales.
\end{abstract}

Keywords: promotion, promotional tool, marketing booklet, brand, brand awareness, unique selling point.

\section{INTRODUCTION}

Sans Power is a trading company selling solar-energy products like solar water pumps and solar panels and provides services before and after purchase to individuals as well as organizations. It is located on Raya Darmo 155-159, Surabaya. This company has a warehouse on Brigjend Katamso IV/200, Surabaya. Sans Power provides three kinds of water pump, such as Submersible, Surface, and Solar Pool Pump. Not only providing water pumps, Sans Power provides three kinds of solar panels, which are monocrystalline, polycrystalline, and thin film. The customers of Sans Power are various, from organization, such as Government, NGOs, and constructors, to individuals, such as private companies, farmers, and breeders. Sans power also has distribution channel across the country, so that it can reach remote or rural areas.

During my three-month internship in Sans Power, I found a problem related to business communication. The problem that Sans Power currently facing is that the sales people have difficulties to explain the unique benefits of Sans Power products. The current marketing tools, company profile booklet and Lorentz catalogue, are not effective enough to cover all information needed by the customers. The company profile booklet only covers general things about solar energy products, and the target of the company profile booklet is not suitable with the current target market reflected on the language used in the booklet. The language used is for youngster (kamu), but the current target market is adult. Also, the content of the current catalogue is only for Lorentz product, with some specification. Because of that, the sales people have difficulties in explaining the uniqueness, especially the services. They cannot explain clearly to the customer who did not have basic information about solar energy. Therefore, the information of Sans Power is still not enough from the current tools. 
I decided to pick that problem as the Business Communication Final Project. Due to the ineffectiveness of the current marketing tools, I will make a new tool to overcome this problem, which is a marketing booklet. The reason why I choose a marketing booklet is it can emphasize features that the previous tools did not emphasize, such as solar system services that Sans Power offers. Therefore, the marketing team can make their jobs easier by using the marketing booklet to promote the products to the potential and existing customers.

There are some theories I used to make this project. In this According to Oxford Dictionaries, "a booklet is a small and thin book with paper covers". However, to complete this project, I found two terms of booklet. There are marketing booklet and sales booklet. Based on Oxford Dictionaries, "marketing is the action or business of promoting and selling products or services". Then, "a sales is the activity or business of selling products". Therefore, marketing booklet is a small book that is used by the company to promote and sell its products or services. Moreover, a sales booklet is a small book which is used by the company to sell its products. Actually, these terms are not significantly different. However, I chose the terms marketing booklet for my Business Communication Project because this booklet will not only selling but also promoting the products or services to its prospects and customers. Malcolm Walsall (n.d.) said there is a few compelling reasons for companies to include marketing booklet in their marketing tools. First, a marketing booklet helps capture the attention of potential customers, especially in the case of small and emerging businesses that are on a tight budget. Second, they are both effective and pocket-friendly than product advertisements on magazines and newspapers, given the fact that prime space on print media is costly. Advertisement space is shared by several businesses competing for public attention, making it a challenge to really get noticed amongst the competition. Third, booklets can focus entirely on the business and its offerings, thereby getting the undivided attention of all potential customers who browse through them. The key, however, is to make the content both interesting and informative, supporting it with appropriate images, and including a call to action. The last one, effective marketing campaigns are all about customer interactions. Booklets are simply just another way to interact with customers and generate leads for the sales teams to follow up. Tara Hornor (2012), an expertise in advertising, branding, and graphic designing, said that there are some crucial elements for a sales booklet. There are able of contents, company overview, case studies, products / services, facilities, how-to-guides, FAQ (Frequently Asked Questions), and company contact information.

\section{METHODOLOGY}

To be able to perform my Business Communication Final Project, there are some steps or procedures that should be done before, during, and after doing the project. First, In order to be able to do the BCFP, I need an approval from the board of examiners. The board of examiners for my proposal are Priska Febrinia Handojo, S.S., MDCC., Drs. Jusuf Imam Ibrahim, M.TESL, and Dwi Setiawan, S.S, MA-ELT, Ph.D. The first step I did to get their approval was writing a proposal of my BCFP. At first, I thought I would make a company profile video for my BCFP. I discussed about the project with the Operational Manager, and she said the company does not have the company profile video yet. Then, I tried to write it on the proposal about what the problem is and why company profile video is a good solution.

Second, I submitted the proposal and did the proposal defense. I tried to explain about my proposal. However, after presenting the problem of the company where I did my internship, the board examiner gave me suggestion to do marketing booklet rather than company profile video because the company's problem was related to sales. After that, I did some consultation with my advisor about this suggestion and proposed my idea to my advisor. After my Idea is approved, I immediately work on changing my project, which is shown in my progress report. This leaded to the permission where I was able to do my project at Sans Power.

After my proposal was accepted by the board examiners, I need to get the approval from the company. The first thing that I did was discuss it with my Operational Manager, Ms. Ema. I explained the project that I would do for this company. She said I needed to discuss it with the director and marketing supervisor. Then, I got to meet the director and explained about the project that I wanted to 
do, and he was interested in doing this project. He also said in advance that he would provide the photographer himself if needed, and I just need to communicate with them. Then, I started to make the proposal for the company, which includes the background of the problems, the solution, and the reason why I want to make marketing booklet. Then, I gave him my proposal. While waiting for the update from the director, I did some interview with some staffs of Sans Power about the current sales tools. This interview apparently proved that making a marketing booklet could be effective to help the current sales tools. Below is the question that I made for the interview.

- What kind of tools do you usually bring when you are doing a sales call for selling Sans Power products?

- Does the sales toll you have help you in sales call? How so?

- Do you think by having a marketing booklet will be more helpful? Why?

- What kind of products do we need to feature in the marketing booklet?

The result of my interview reached a conclusion that a marketing booklet will be more effective and helpful. They said that the current tools could not help them when the customers asked some detailed question, such as services that they will get when they buy Sans Power products. They wanted to include the installation service that they have, so that they can explain more in details to the customers. They also said that there is no information about the uniqueness of their product, which is using DC electric current that shows the efficiency their products have.

Next, I made a letter of agreement or contract for them while waiting for his answer. After three weeks, I had the opportunity to meet the director again. He asked me about my project at the company and the feature I will input in the booklet. I also showed the result of the interview with the staffs. Finally, he agreed to let me do my project at the company and I showed him the contract. We discussed about my proposal in details for every package that I wrote in proposal. Then, he agreed with the contract and chose the first option from my offer and Rp. 1.200.000,- is given for this project.

After my proposal got accepted by the company including the cost of making the project, I started my project. First, I need to know the unique selling points of Sans Power and its products. I collected some information about the company. I studied directly to the products and services of Sans Power in detail. I also asked further information about them from the Sales and Marketing team at Sans Power. Then, I know about the uniqueness of its products, which is it provides high-efficient products, which are different from other brand. The electric current used is DC, while other brands use AC electrical current. DC electrical current will make the water pumps work longer than AC electrical current. Then, I created the content that I wanted to input in the marketing booklet. The contents of the marketing booklet were table of contents, about Sans Power, Products, Services, and Contact. As soon as I finished making the content, I had a discussion with the director and the marketing staffs. They gave me some advice to add the installation services they had talked when I interviewed them. Besides, they wanted to add the extra services or benefits the customers will get when they buy Sans Power's products.

\section{FINDINGS AND DISCUSSION}

As aforementioned, I aim to create a marketing booklet for Sans Power by making the content and the design of the booklet. The marketing booklet is consist of eighteen pages including the covers. Besides, the size of the marketing booklet is A5. To make this marketing booklet, I used green tosca and white as the main color for the background. I chose green tosca to represent the logo of Sans Power. It is green because green is related to eco-friendliness. In addition, green also means bio- (prefix), which is life. As the main resource or energy of the product is from sunlight, it is an important element in life. It use tosca to adjust to current design trends. I chose white as the base for this booklet to make it looks mild and neat. The layout design design of the marketing booklet was done by the graphic designer and me. Actually, I made the main concept and the graphic designer mad the layout design of the marketing booklet.

For the contents of the marketing booklet, I did not use all of the components that I mentioned in Chapter 2 because I found that there were some components thate was inappropriate to be included in the marketing booklet of Sans Power. Those are FAQ (frequently Asked Questions) and How-to Guides. 
The use of FAQ in this booklet is inappropriate because there was the customers will ask no similar question depending on each situation. Besides, I did not include the How-to Guide because this kind of component is often used in a big corporate which has a complicated system. Therefore, for this marketing booklet, I chose six appropriate components, such as Table of Contents (Content), company overview (About Sans Power), case studies (Our Projects), products / services, and company contact information (Contact). I chose to make a marketing booklet with those elements because I thought those elements are the main information needed by the prospects in order to buy Sans Power's products. Mainly, people who want to buy solar energy products will look about the information about Sans Power, what products and services it offers, how trusted Sans Power is, and how to contact the company. Thus, I think it is important for this marketing booklet to have About Sans Power, Products, Sevices, Our Project, and Contact $\mathrm{s}$ its components.

In addition, the order of the components inside the marketing booklet will also be my consideration in making this marketing booklet. In the front cover, I mostly use green tosca to represent the logo of Sans Power. After that, I put sun flower on the right corner because it has similar pronunciation and to symbolize natural elements. I also put the logo and make it as the title of the marketing booklet.

The second part is Contents. This section is important for the prospects who want to find certain information about Sans Power. It can help them navigating to the page of the information they need without opening every page of the marketing booklet. Therefore, the table of content part must be the first component in the marketing booklet. I chose to use only "Content" to get rid of stiff impression in the marketing booklet.

The third part is the company overview. The function of this part is to help Sans Power to introduce more about its company. To make this section, I used two questions: what and why. The first "What is Sans Power?". It can help Sans Power to define its company to the prospects and customers. This part should be the first order because after the readers read the booklet's title, which is "Sans Power", they will start asking about what kind of company Sans Power is. After that, ther will be "Why Sans Power?". The use of this section is to convince the prospects and customers to choose Sans Power rather than other companies. This section came in the last part ecause after they know the basic information of Sans Power, they would have the willingness to know the strengths of Sans Power. Thus, the key benefit of the company overview section is to show the strengths of Sans Power so that the company can convince the prospects and the customers to buy its products.

After the prospects get attracted by the company strengths, the next information will be the product of Sans Power. This part become the third because once the prospects read the information about the company, they will automatically get more curious about what products Sans Power sells. Sans Power has two categories of products, which are solar water pumps and solar panels. I put three kinds of products for each category based on the function. For solar water pumps, there are three kind of them, which are submersible solar pump, surface solar pump, and solar pool pump. There are also three kinds of solar panels, which are thin film, monocrystalline, and polycrystalline. After that, the customers will be able to know what products Sans Power sells and have the interest to buy the product based on their needs. Moreover, the prospects will also want to know about the differences and the function of each products. Therefore, in this part I also mention some description about each kinds of the products. I did not put the price here because each types of the products have many different types and codes based on the specification. Therefore, I did not put the price in the marketing booklet.

The next part is services provided by Sans Power. Service here means installation services. In here, I mentioned three kinds of installation services Sans Power provides, which are On-Grid solar system, Off-Grid solar system, and Solar Water Pump system service. Most of the customer must be wondering how the products is installed. That is why this part will be right after the products part. I also add "Extra Services" after this part. It contains the benefit the customers will get when they buy Sans Power's products. They will know that they will get extra service before and after they purchase Sans Power's products. This part also plays an important role to make the prospects and customers decide whether it will fulfill their needs or not. 
The next part is case studies with headings "Our Projects". In here, I did not put any explanation; instead, I put some pictures of the project Sans Power has been done until now. I put this after the services part to emphasize that Sans Power has already done many projects, and of course, Sans Power is credible. The last part is the contact information page. In here, prospects can find the address, the phone number, the fax number, and the website of Sans Power's headquarter and customer service. I put this information in the last page because after the prospects shape a certain image of Sans Power, choose a type of product they want, and know what benefits services and benefits the company offers, it is the time for the prospects to contact Sans Power to place an order. Besides, when the prospects need other information, they can use this par as a chance to get more information. Therefore, it is appropriate to put the contact information in the last page.

\section{CONCLUSION}

The problem that Sans Power currently facing is that the sales people have difficulties to explain the unique benefits of Sans Power products. The current marketing tools, company profile booklet and Lorentz catalogue, are not effective enough to cover all information needed by the customers. Because of that, the sales people have difficulties in explaining the uniqueness, especially the services. Therefore, the information of Sans Power is still not enough from the current tools. To overcome this problem, Sans Power needs a marketing booklet for its marketing tools.

There are six component in this marketing booklet, which are "Contents", "About Sans Power", "Products", "Services", "Extra Services", "Our projects", and "Contacts". Those components will help Sans Power in solving its problems because it can increase consumers' awareness of Sans Power's products and it will attract the prospect to buy its products.

The marketing booklet is hoped to be a beneficial tool for Sans Power. The sales and Marketing team can use the marketing booklet to give them facility in selling Sans Power's products well. Furthermore, the marketing booklet will help the customer to know more about Sans Power products and services. The last advantage is the marketing booklet will help to increase the sales of Sans Power. I use English version because of the requirement from the department. However, I suggest Sans Power to make the Indonesian version to expand the scale of the business and target market.

My suggestion for the next EBC students who will do a similar project in the future is they should find a good company for their internship. It will help them to sharpen the skills they got in English Business Communication in a good company, and also they will be easily do their project if they have good image in the company. The next one, it will be better if they build a good relationship between themselves, their supervisor, and the employee during their internship period. It will be better to try explaining the goal of their internship to them that they will contribute a project, which will benefits them in the future. Then, identify the problem and find the uniqueness through Google form or interviewing the customers and workers. Next, after they know and understand the problem and the strength, or the uniqueness of the company, they can come up with their final project idea. I suggest getting an immediate approval from either their examiners or their supervisor because when they give them an approval, they can immediately meet the person who will take the decision from the company. Thus, they need to arrange time wisely and not to procastinate in doing this project.

\section{REFERENCES}

Booklet. Retrieved from http://www.oxforddictionaries.com/definition/english/booklet

Hornor, T. (2012). Tips for Better Sales Booklets. Retrieved from http:// www.business2community.com/marketing/tips-for-better-sales-booklets-0274390\#R 1uptM43GLZdf5S2.99

Walsall, M. (n.d.). B2B Marketing. The importance of brochure printing as a marketing tool. Retrieved from https://www.b2bmarketing.net/en-gb/resources/blog/importance-brochure-printingmarketing-tool 